\title{
Homilije sv. Hieronima v srednjeveškem cerkvenoslovanskem prevodu (v Propriumu de tempore)
}

\author{
St. Jerome's Homilies in the Medieval Old-Church \\ Slavonic Translations (in Proprium de tempore)
}

Izvleček: Berila iz homilij sv. Hieronima so bila prevedena iz latinščine v cerkveno slovanščino verjetno ob nastanku cerkvenoslovanske različice brevirja sredi 13. stoletja, ko je papež Inocenc IV. odobril uporabo slovanske liturgije pri benediktincih v Senju in na Krku. Avtorji hrvaškoglagolskega brevirja so uporabljali starejše starocerkvenoslovanske prevode svetopisemskega besedila, preostala besedila - med njimi tudi homilije sv. Hieronima - so prevajali naravnost iz latinskega brevirja, zato lahko v njih najdemo karakteristične prvine aktivno uporabljane hrvaške cerkvene slovanščine. V prispevku preverjamo pravilnost navedbe Hieronimovega avtorstva besedil $\mathrm{v}$ brevirju in pokažemo, da so nekatere leksikalne prvine prevoda homilij enake kot tiste iz bibličnih besedil v hrvaškoglagolskih knjigah južne tekstološke skupine.

Ključne besede: homilije, hrvaška glagolica, brevir, prevod, sv. Hieronim

Abstract: Readers from the homilies of St. Jerome were translated from Latin into Church Slavonic, probably when the Church Slavonic version of the breviary was created in the mid$-13^{\text {th }}$ century, when Pope Innocent IV. approved the use of Slavic liturgy by the Benedictines in Senj and Krk. The authors of the Croatian-Glagolitic breviary used older Old-Church Slavonic translations of the biblical text, other texts - among them the homilies of St. Hieronymus - were translated straight from the Latin breviary, so we can trace in them the characteristic elements of actively used Croatian Church Slavonic. In this paper, we review the authenticity of the Jerome's authorship of the texts in the breviary and show that some of the lexical elements of the translation of homilies are the same as those of the biblical texts in the Croatian text books of the southern textual group.

Key Words: homilies, Glagolitic language, breviary, translation, St. Jerome 


\section{Hrvaškoglagolski prevod brevirja}

Najverjetneje sredi 13. stoletja, ko je papež Inocenc IV. senjskemu škofu Filipu (1248) in škofu Fruktuosu s Krka (1252) uradno dovolil uporabo slovanske liturgije pri benediktincih iz Omišlja na Krku, je nastal unikatni prevod brevirja v slovanski liturgični jezik - cerkveno slovanščino, ki je zapisan v hrvaški različici izvirne slovanske pisave glagolice. Glagolico so takrat pogosto imenovali pisava sv. Hieronima, in prav Hieronimova avtoriteta je najbrž tudi pomembno prispevala k papeški odobritvi slovanske liturgije na Krku.

Do danes se je ohranilo v celoti ali skoraj v celoti 20 rokopisnih hrvaškoglagolskih brevirjev iz 13.-15. stoletja, ki so predtridentinskega tipa (Breviarium Romanum secundum consuetudinem Romanae Curiae) (Vajs 1908, 232-233) in vsebujejo proprium de tempore (7 kodeksov) ali proprium sanctorum in commune sanctorum (2 kodeksa) ali vse naštete dele (11 kodeksov) (Pantelić in Nazor 1977, 10-12). Besedila cerkvenih očetov se pojavljajo v različnih nokturnih in so označena v skladu z latinskim brevirjem kot »slovo« (lat. sermo) ali kot »omiliê« (lat. homilia), če gre za razlago odlomka iz evangelija. V celotnem hrvaškoglagolskem brevirju najdemo samo dve besedili naslovljeni kot »slovo sv. Eronima« in 20 besedil kot »omiliê sv. Eronima«, pri čemer jih 18 razlaga berila iz Evangelija po Mateju, dve pa sledita odlomku Evangelija po Luki. V prispevku se bomo osredotočili na preučevanje izbranih leksikalnih prvin prevoda beril iz homilij sv. Hieronima, uvrščenih v Proprium de tempore hrvaškoglagolskega brevirja, ker imamo za homilije iz tega dela na voljo variante iz večine ohranjenih rokopisov in dveh tiskov hrvaškoglagolskega brevirja (Stankovska 2001, 32-295). Osvetlili bomo tudi pojavnost besedil Hieronimovih homilij in v Mignejevi latinski Patrologiji (v nadaljevanju PL) preverili pravilnost navajanja njegovega avtorstva $v$ raziskanih brevirjih. ${ }^{1}$

1 Seznam okrajšav obdelanih rokopisov in prvotiskov hrvaških brevirjev je naveden na koncu članka. 


\section{Pojavnost Hieronimovih homilij v Propriumu de tempore hrvaških glagolskih brevirjev, navajanje avtorja}

V Propriumu de tempore ohranjenih hrvaškoglagolskih brevirjev najpogosteje najdemo 10 homilij, naslovljenih z imenom sv. Hieronima. Zaradi preglednosti navajamo seznam homilij, ki so v hrvaškoglagolskem brevirju pripisane sv. Hieronimu z navedbo dneva, za katerega so namenjene kot berilo, začetnim verzom evangelijskega odlomka, imenom avtorja, referenco v PL in eventualno navedbo druge homilije, ki je v nekaterih brevirjih umeščena na isti dan:

I. dan sv. Štefana (Mt 23,34), S. Hieronymi: Commentariorum in Evangelium Matthaei lib. IV, cap. 23 (PL26: 172), vsi ohranjeni brevirji.

II. dan Spomina nedolžnih betlehemskih otrok (Mt 2,13), S. Hieronymi: Commentariorum in Evangelium Matthaei lib. I, cap. 2 (PL26: 27).

Nekateri brevirji - večina starejših brevirjev, ki so nastali na otoku Krku oz. v Istri (najstarejši VB1 iz 13.-14. stoletja, KOS in LJ iz 15. stoletja) - imajo na ta dan isto evangelijsko berilo, homilijo Bede Častitljivega, homilia IX., In die festo Innocentium (PL94: 50). Brevir N1 iz 15. stoletja pa ima najprej Hieronimovo homilijo, zatem pa še Bedovo.

III. Vigilia Epiphaniae (Mt 2,19), S. Hieronymi: Commentariorum in Evangelium Matthaei lib. I, cap. 2 (PL26: 28), vsi brevirji.

IV. Torek 3. tedna velikega posta (Mt 23,1-3), S. Hieronymi: Commentariorum in Evangelium Matthaei lib. IV, cap. 23 (PL26: 167), vsi brevirji.

V. 3. nedelja velikega posta (Lk 11,14), kombinacija Hieronimovih razlag Matejevega evangelija (Divina bibliotheca 32, Evangelium secundum Matthaeum, PL29: 556), ki tvorijo jedro besedila, z vstavljenimi citati homilije Bede Častitljivega (homilia XLIX., In dominica tertia quadragesimae, 
PL 94: 380), ki je bila uvrščena na ta dan v drugem tipu brevirja, ki je v hgl. verziji ohranjen samo v odlomku t. i. Ljubljanskega homiliarja. ${ }^{2}$

VI. Torek 4. tedna velikega posta (Mt 18,15), s. Augustini: Sermones ad populum. De scripturis, Sermo 82, cap. 3 (PL38: 507) Sermo 16. de Verbis Domini, tom. 10 post initium, vsi brevirji.

VII. Sreda 4. tedna velikega posta (Mt 15,1-2), S. Hieronymi: Commentariorum in Evangelium Matthaei lib. II, cap. 15 (PL26: 105), vsi brevirji.

VIII. 8. nedelja po binkoštih (Lk 16,1), s. Hieronymi: Epistolae secundum ordinem temporum distributae, Epistola 121, cap. 6 (PL30: 1018), vsi brevirji.

IX. 23. nedelja po binkoštih (Mt 9,18), S. Hieronymi: Commentariorum in Evangelium Matthaei lib. II, cap. 9 (PL26: 58), vsi brevirji.

X. 24. nedelja po binkoštih (Mt 24,15), S. Hieronymi: Commentariorum in Evangelium Matthaei lib. IV, cap. 24 (PL26: 177), vsi brevirji.

Iz navedenega sledi, da v Propriumu de tempore hrvaškoglagolskih brevirjev sicer najdemo prevode 10 homilij, naslovljenih z imenom sv. Hieronima, vendar homilija na torek 4. tedna velikega posta ni Hieronimova, ampak Avguštinova (PL38: 507). V besedilu za 3. nedeljo velikega posta so na odlomek, ki se začne z vrstico Lk 11,14, kombinirani komentarji Hieronima na 12. poglavje Evangelija po Mateju (PL29: 556) s homilijo Bede Častitlivega (PL94: 380). Dejansko je torej v Propriumu de tempore hrvaškoglagolskih brevirjev eno homiletično besedilo večinoma sestavljeno iz Hieronimovih komentarjev in 8 Hieronimovih homilij. Trije od preučevanih brevirjev (VB1, KOS, LJ) vsebujejo eno Hieronimovo homilijo manj, ker imajo na dan Spomina nedolžnih betlehemskih otrok namesto Hieronimove homilijo Bede Častitlivega (PL94: 50).

2 V odlomku t. i. Ljubljanskega homiliarja iz 13. stol., ki se hrani v Narodni univerzitetni knjižnici v Ljubljani s signaturo Ms 368/5 in jezikovno spada med brevirje severne tekstološke skupine (Stankovska 2013, 431). 
V hrvaškoglagolski tradiciji je očitno obstajal tip brevirja, ki je vseboval še eno homilijo sv. Hieronima - na četrtek 3. nedelje velikega posta, namreč besedilo na Güssingškem fragmentu naznanja homilijo sv. Hieronima na evangelijski odlomek, ki se začne z verzom Lk 4,38, na katero imajo preostali ohranjeni brevirji homilijo sv. Ambroža (Birkfellner 1965, 67-110).

V nadaljevanju prispevka se bomo ukvarjali z besedili beril Hieronimovih homilij, torej tistih, ki so na našem seznamu navedene pod številkami 1-4 in 6-10, s katerimi jih bomo tudi označevali (npr. H1).

\section{Analiza pojavnosti izbranih leksemov v homilijah sv. Hieronima kot ekvivalentov za latinske izraze, prevajalske rešitve specifičnih prvin Hieronimovih besedil}

Besedila homilij in analiza oziroma ocenjevanje njihovega prevoda iz latinščine v hrvaško cerkveno slovanščino imajo svoje posebnosti v primerjavi z bibličnimi besedili v hrvaškoglagolskih spomenikih, ki so bila večinoma predmet raziskav v preteklosti. Pri analizi prevoda homiletičnih beril in njegovih jezikovnih prvin je treba paziti na prisotnost svetopisemskih citatov v besedilih homilij, saj so vsaj nekatere med njimi prevajalci najbrž znali na pamet in so jih zato lahko uporabili v ustaljeni obliki, ki se je morda nekoliko razlikovala od običajne rabe. Glagoljaši so namreč uporabljali starejše dostopne prevode Svetega pisma oz. njegovih delov (npr. starozavezna besedila, evangelij, psalter v celoti ipd.), ki so v nekaterih brevirjih (s Krka in iz Istre) prevzeti brez popravkov (severna tekstološka skupina), v drugih brevirjih (z območja Zadra in Krbave) pa so popravljeni tako, da bi čim bolj natančno ustrezali latinski različici (južna skupina). ${ }^{3}$ Edina izjema je psalter, ki večinoma sledi starocerkvenoslovanskemu prevodu psalterja v njegovi prvi redakciji (Valjavec 1889/1890, 1-72) s samo minimalnimi posegi v jezik, predvsem na glasoslovni ravni.

V nekaterih svetopisemskih besedilih je opazna ena varianta v severni tekstološki skupini brevirjev, v južni skupini brevirjev pa druga, prilagojena

3 K severni tekstološki skupini se večinoma uvrščajo brevirji VB1, VB2, VB3, VO, MA, KOS, PAD, k južni pa VAT, MO, DR, PM, ILL, DAB, D215, Vat19. Preostali se označujejo za mešane, ker nekatera berila spadajo bolj k eni tekstološki skupini, druga k drugi. 
latinski različici. Take različice so lahko vseh vrst (glasoslovne, skladenjske, oblikoslovne), mi pa se bomo osredotočili na razlike v uporabljenih leksemih - pojavljajo se sinonimne dvojice, v katerih en leksem lahko označimo kot "paleoslavizem «, ${ }^{4}$ drugi pa pripada aktivni uporabi v hrvaški različici cerkvene slovanščine. Podobnih razlik v homiletičnih besedilih skoraj ni, razen $\mathrm{v}$ redkih svetopisemskih citatih. V homiletičnih besedilih tako najdemo večinoma tri vrste variant:

(1) očitne napake, nastale pri prepisovanju, ki se kažejo kot popačeno besedilo ali izpusti, npr. H1: z'najutb kog'da s'lovo izreći N2 PM ILL BAR DAB DR D2 MO namesto z'najutb kog'da podobajut's 'lovo izreći VB1 VO VAT LJ N1 MA KOS za lat: qui noverint quando debeant proferre sermonem;

(2) redke leksikalne variante, ko se en leksem nadomešča s sinonimom, npr. v H1: $k^{\prime}$ telesi gospod'nju podobit' N2 VAT MO ILL D2 BAR DR PM se pojavi namesto $k^{\prime}$ obrazu gospod'nju VB1 VO LJ MA N1 KOS za lat: ad personam Domini;

(3) besedne (npr. govoriti namesto glagolati) ali glasoslovne (večinoma rotacizem, npr: more namesto može, ere namesto e ěe, prorenete namesto proženete) variante v nekaterih (MA, ILL) rokopisih 15. stoletja.

Zato ni smiselno, da bi se podrobneje ukvarjali z analizo variant homiletičnih besedil $\mathrm{v}$ posameznih brevirjih (tako kot je to smiselno pri svetopisemskih besedilih). Namesto tega se bomo osredotočili na ugotavljanje pojavnosti leksemov iz sinonimnih dvojic (redkeje trojic) starocerkvenoslovanskih 5 ali hrvaškocerkvenoslovanskih izrazov v prevodih beril iz Hieronimovih homilij. V nadaljevanju (3.1) bomo iz prevodov Hieronimovih besedil izbrali lekseme iz sinonimnih dvojic, ki so bile določene na podlagi raziskave nekaterih svetopisemskih besedil, in s pomočjo njihovih ustreznic v latinskih besedilih našli vse možne variante prevoda latinske besede v tukaj obravnavanih Hieronimovih besedilih. Poleg tega

4 Takšno klasifikacijo predlaga H. Bauerová in dodaja konkretne primere leksemov (2004, 567-575).

5 Kot starocerkvenoslovanske v tem prispevku dosledno označujemo lekseme, ki se pojavljajo v starocerkvenoslovanskih rokopisih do 11. stol. in so obdelani v Slovarju starocerkvenoslovanskega jezika (Kurz, Hauptová 1966-1997). 
bomo skušali izpostaviti prevode nekaterih leksemov ali besednih zvez, specifičnih za obravnavana besedila (3.2).

\subsection{Izbrane besede iz Esterine knjige, Knjige Modrosti, prve in druge knjige Makabejcev in Jobove knjige}

Med izbranimi so latinske besede, za katere se v hrvaškoglagolskih brevirjih lahko uporabljajo leksikalne dvojice, ugotovljene $\mathrm{z}$ analizo beril iz Esterine knjige, knjige Modrosti, prve in druge knjige Makabejcev: convivium, diadema, corona, dux, exercitus, eunuch, gens, inutilis, invenire, Iudaei, melior, mirari, populus, princeps, provincia, regnare, regnum, res, rex, sacerdos, templum (Stankovska 2017, 193-221). Izbrane so tudi besede z ekvivalenti sinonimnih dvojic, ugotovljenih v besedilu Jobove knjige: inimicus, amicus, aurora, camela, holocausta, nuntius, satan, simplex, tangere in ventus, timere, terra, pulvis, filius, angelus (Stankovska 2019, 207-208, 210-211).

Od naštetih izrazov iz izbranih besedil Stare zaveze (v nadaljevanju SZ) se v latinskem besedilu obravnavanih Hieronimovih berilih ne pojavljajo: convivium, diadema, dux, exercitus, eunuch, inutilis, melior, mirari, provincia, res, inimicus, amicus, aurora, camela, holocausta, nuntius, satan, simplex (samo simpliciter), ventus, pulvis.

Problematika besed anjelb (angelus), zemlja (terra), (u)boêti se (timere) in sins (filius) ter njihovih latinskih oz. grških ustreznic v Jobovi knjigi je posebna (v latinskem besedilu se na različnih mestih izmenjujeta dve ustreznici za en grški izraz), zato jih ne gre primerjati s prevodi v Hieronimovih besedilih. Leksem filius pa bomo obravnavali posebej.

Zaradi večje preglednosti navajamo ustreznice za izbrane latinske izraze iz Hieronimovih in izbranih svetopisemskih besedil v razpredelnici (tab. 1), iz katere je mogoče razbrati, da se večina leksemov, ki so uporabljeni v brevirjih južne tekstološke skupine, pojavlja tudi v prevodu Hieronimovih besedil: 


\begin{tabular}{|c|c|c|c|c|}
\hline Lat. beseda & $\begin{array}{l}\text { Hieronimove } \\
\text { homilije - pre }\end{array}$ & $\operatorname{vod}$ & SZ besedilo - sev. & SZ besedilo - juž. \\
\hline Corona & věnacь (H4) & & koruna & věnьсь \\
\hline Gens & $\begin{array}{l}\text { narodь (H1, } \\
\text { H4) }\end{array}$ & & narodь & narodb/êzikь \\
\hline Invenire & $\begin{array}{l}\text { obrěsti (H2, } \\
\mathrm{H} 8-2 \mathrm{x})\end{array}$ & & obrěsti & obrěsti/naiti \\
\hline Iudaeus & $\begin{array}{l}\text { ijuděiski } \\
\text { (H1) } \\
\text { juděja (H2) }\end{array}$ & & žide & ijuděi \\
\hline Populus & $\begin{array}{l}\text { ljudi (H1, } \\
\mathrm{H} 4-2 \mathrm{x})\end{array}$ & plkь (H4) & plьkь & ljudi/ljudь \\
\hline Princeps & $\begin{array}{l}\text { knězb } \\
(\mathrm{H} 9-4 x)\end{array}$ & & knězb/v'ladika & v'ladika/ knězb \\
\hline Regnare & $\begin{array}{l}\text { cěsarstvovati } \\
\text { (H3 cit.) }\end{array}$ & & cěsarstvovati & $\begin{array}{l}\text { cěsarstvovati/ } \\
\text { vladati }\end{array}$ \\
\hline Regnum & $\begin{array}{l}\text { cěsarstvie } \\
\text { (H3) }\end{array}$ & & $\begin{array}{l}\text { cěsarstvie/ } \\
\text { kralevstvie }\end{array}$ & cěsarstvie \\
\hline Rex & cěsarı (H1) & & cěsarb & kralı/ cěsarı \\
\hline Sacerdos & $\begin{array}{l}\text { erěi (H1- } \\
2 x, H 3, H 4, \\
\text { H7-2x) }\end{array}$ & & zakonnikb & erěi \\
\hline Tangere & $\begin{array}{l}\text { (do)taknuti } \\
(\mathrm{H} 9-4 \mathrm{x})\end{array}$ & $\begin{array}{l}\text { kosnuti } \\
\text { 1x var } \\
\text { v N2 VB1 }\end{array}$ & kosnuti & taknuti \\
\hline Templum & $\begin{array}{l}\operatorname{cr}(\mathrm{b}) \mathrm{k}(\mathrm{b}) \\
\text { vь H1-6x, } \\
\text { H7-2x, } \\
\text { H10-3x) }\end{array}$ & & hramb/cr(ь)kavb & cr(ь)kavь \\
\hline
\end{tabular}

Tab. 1.

\subsection{Izbrane besede iz homilij sv. Hieronima}

Poleg besed, ki so bile izbrane na podlagi preučevanja delov starozaveznih besedil, smo v Hieronimovih besedilih opredelili latinske lekseme, katerih prevod v cerkveno slovanščino je iz različnih razlogov zanimiv. To so: scriba, hebraeus, hebraicus, blasphemare, filius, pecuniae, villicus, oikonomos:

scriba - beseda se pojavlja desetkrat in $\mathrm{v}$ osmih primerih je prevedena $\mathrm{z}$ izrazom knižnikb (H3, H4-2x, H7-2x, H8-3x), razen dveh primerov v H1, kjer se pojavi $k^{\prime}$ nigočii. To se je verjetno zgodilo zaradi pojava istega ekvivalenta v citatu iz Matejevega evangelija (Mt 23,34) neposredno pred homiletičnim berilom in tudi v prvem primeru pojava $v$ homiliji. Oba ekvivalenta se pojavljata že v najstarejših starocerkvenoslovanskih spomenikih, pri 
čemer se kbnižnikb ocenjuje kot starejši, cirilo-metodijski izraz in kbnigočii kot mlajša, preslavska (bolgarska) inovacija. V samem besedilu najstarejših evangelijskih starocerkvenoslovanskih prepisov se taka distribucija potrjuje (Temčin 1995, 64-81). V psalterju (tudi v hrvaškoglagolskih) je samo na enem mestu $k^{\prime}$ nižnik (Ps 44,2), kar bi lahko bilo povezano tudi $\mathrm{z}$ uporabo te besede $\mathrm{v}$ prevodu homiletičnega besedila, $k^{\prime}$ nigoči $i \mathrm{v}$ citatu iz evangelija pa lahko posredno potrdi dejstvo, da je večina evangelijskih besedil v hrvaškoglagolskih knjigah v varianti, ki se večinoma označuje kot preslavska redakcija stsl. prevoda evangelija (Stankovska 2012, 76-89);

hebraeus - na dveh mestih je ekvivalent evrěiski (H1, H2) in hebraicus s prevodom židovsk' (H3). Zanimiva je ravno distribucija poimenovanj s korenoma evrěi-in žid-v prevodu;

blasphemare - se v analiziranih besedilih pojavlja enkrat (H10): protivu namb hulilb estb za lat.: contra nos blasphemavit. Glagol huliti je uporabljen z vezljivostjo "protivu « $z$ dajalnikom, kar je inovacija hrvaške cerkvene slovanščine v nasprotju s starocerkvenoslovansko vezljivostjo z brezpredložnim dajalnikom ali tožilnikom (Kurz in Hauptová 1966-1997).

Pri prevajanju nekaterih latinskih izrazov so prevajalci očitno imeli težave z izbiro pravega slovanskega izraza predvsem tam, kjer je šlo za razlago, preneseni pomen ali večpomenskost izraza, npr.:

filius - večinoma je preveden kot sinb kot v H1 (6x): Zaharija sinb varahiins za lat.: Zacharias filius Barachiae in H1 (2x): sinb ioadin' za lat.: filius Ioiadae, v H2 (skupno 4x) enkrat kot sinb, ko se govori o Jezusu, drugič je množina filii prevedena kot čeda, ko se govori o Rahelinih otrocih, ki jih objokuje, gre pa za citat iz Jeremije 31,15. Ko gre na dveh naslednjih mestih spet za Raheline otroke, vendar se ne citira več Sveto pismo, se obakrat pojavi prevod sinb. V H3 (2x) se pojavi prevod sinb prvič, ko se govori o Jezusu, in drugič, ko gre za Herodovega sina. V H7 (skupno 3x) spet sinb, ko se govori o sinu Božjem, dvakrat pa zasledimo prevod čeda v besedilu homilije, ki se nanaša na citat iz evangelija po Luki $(10,7)$. In še dvakrat sinb, ko se govori o sinovih očeta $\mathrm{v}$ H8, in čeda, ko se govori o otrocih v trebuhu nosečnic v H10; 
pecuniae - enkrat se prevaja kot penězi (H7), drugič sreb ro (H8), kar je verjetno odvisno od dojemanja konteksta v dani homiliji;

villicus - pojavi se štirikrat (H8) v prevodu pristav'nikb (po citatu Lk 16,1), oikonomos pa trikrat (H8) - enkrat preveden kot pristav'nikb (enako kot villicus), v nadaljevanju besedila pa kot obaritel $\mathrm{z}$ variantami obarovatelb, obranitelb, reditelb, kar je najbrž posledica tega, da so prevajalec in pisarji iskali pravi izraz. Kontekst Hieronimovega besedila, kjer se prvič pojavita obe besedi:

Homo quidam erat dives, qui habebat villicum (Lk 16,1) sive dispensatorem, hoc enim oikonomos significat. Villicus autem proprie villae gubernator est, unde et a villa villicus nomen accepit. V prevodu: č(lově)kb et(e) rb bogatb iměše pristavnika ili span'žatura. Se že ime zn(a)m(e)nuetb pristavnikb. êko vlaćee vsi udržatelb e(stb). otnudeže ot sela ime priêtb.

Podobne težave so prevajalcem povzročali tudi različni konteksti, ki se ponavadi $v$ prevodih svetopisemskih besedil v staro cerkveno slovanščino ne pojavljajo, npr. zvezo »de statua Hadriani equestri« so prevedli na neki način precej izvirno kot »ot an'driêna kon'skago obraza«.

\section{Sklep}

V besedilu homilij skoraj ni besednih, skladenjskih ali besedilnih variant med raziskovanimi hrvaškoglagolskimi brevirji.

Pri analizi prevodov besedil homilij sv. Hieronima v Propriumu de tempore hrvaškoglagolskih brevirjev se potrjuje, da je treba poleg preverjanja avtorstva navedenih beril paziti tudi na strukturo homiletičnih besedil in pri ocenjevanju uporabe prevodnih sredstev razlikovati med citiranim svetopisemskim besedilom v homiliji in preostalim besedilom, ker se lahko v obeh vrstah besedila razlikuje ekvivalent za isto latinsko besedo (npr. $k^{\prime} n i z ̌ n i k \mathrm{v}$ besedilu in $k^{\prime}$ nigočii $\mathrm{v}$ evangelijskih citatih za lat. scriba).

Pri primerjavi z besedami, ki imajo sinonime v svetopisemskih besedilih hrvaškoglagolskih spomenikov, se pokaže, da večina izrazov, ki so jih uporabili pri prevajanju homiletičnih besedil, sovpada z izrazi, ki so tipično 
rabljeni v svetopisemskih besedilih v rokopisih t. i. južne tekstološke skupine (npr. erěi za sacerdos, taknuti za tangere, věnьcь za corona idr.).

Prevajalci so se morali spopasti s prevajanjem nekaterih besed ali razlag, ki so zahtevne za prevod, npr. poimenovanje funkcij v gospodarstvu, kot sta izraza villicus in oekonomos, in razlaga nastanka besede villicus "pristav'nikb"(iz samostalnika villa »selo«). Večinoma jim ni uspelo ohraniti vseh pomenskih razsežnosti izvirnega besedila.

\section{Kratice}

BAR Baromićev, 1493, papir, tisk.

DAB Dabarski, 1486, pergament, Zagreb, Archiv HAZU, sign. IIIc21.

DR Dragučki, 1407, pergament, Zagreb, Arhiv HAZU, sign. IIIb25.

D215 iz arhiva sv. Petra, 15. stol., pergament, Rim, Bibl.

Apostolica Vaticana, sign. Cap. S. Pietro D215.

ILL Vatikanski 10., 1485, pergament, Rim, Bibl. Apostolica Vaticana, sign. Borg. Illir. 10.

Kos Kosinjski, prvotisk, 1491, papir.

IJ 2. ljubljanski, 15. stol., pergament, Ljubjana, NUK, sign. Ms 163.

MA Mavrov, 1460, pergament, Zagreb, NSK, sign. R 7822.

Mo Moskovski, 1442-43, pergament, Moskva, RGB, Zbirka Sevastyanov, sign. Fond 270, 51.

N1 1. novljanski, 1459, pergament, Novi Vinodolski, župnišče.

N2 2. novljanski, 1495, pergament, Novi Vinodolski, župnišče.

PAD Padovanski, pol. 14. stol., pergament, Padova, Biblioteca Universitaria sign. MS 2282.

VAT Vatikanski 5., pol. 14. stol., pergament, Rim, Bibl. Apostolica Vaticana, sign. Borg. Illir. 5.

Vat19 Vatikanski, 1465, pergament, Rim, Bibl. Apostolica Vaticana, sign. Vat. Slav. 19.

VB1 Vrbniški prvi, 13.-14. stol., pergament, župnišče v Vrbniku.

VB2 Vrbniški drugi, 14. stol., pergament, župnišče v Vrbniku.

VB3 Vrbniški tretji, 15. stol., pergament, župnišče v Vrbniku.

Vo brevir Vida iz Omišlja, 1396, pergament, Dunaj,

Österreichische Nationalbibliothek, sign. Cod. Slav. 3. 


\section{Reference}

Bauerová, Helena. 2004. Ke klasifikaci lexika charvátskohlaholských textů. V: Ana-Marija Dürrigl, Milan Mihaljević, Franjo Velčić, ur. Glagoljica i hrvatski glagolizam, 567-575. Zagreb - Krk: Staroslavenski institut.

Birkfellner, Gerhard. 1965. Das Güssinger Brevierfragment. Wiener slavistisches Jahrbuch 12: 67-110.

Kurz, Josef in Zoe Hauptová, ur. 1966-1997. Slovník jazyka staroslověnského. Praha: Academia.

Pantelić, Marija in Anica Nazor. 1977. II. Novljanski brevijar. Hrvatskoglagoljski rukopis iz 1495. godine. Župni arhiv Novi Vinodolski. Fototipsko izdanje. Zagreb: Staroslavenski institut Svetozar Ritig i Turistkomerc.

Stankovska, Petra. 2001. Rekonstrukce charvátskohlaholského homiliáre. Disertační práce Filozofická fakulta Univerzity Karlovy v Praze.

- - -. 2012. Odkaz prěslavské školy v chorvatskocírkevněslovanských liturgických památkách. Preslavska knižovna škola 12: 76-89.

- - -. 2013. K obsahu zlomku tzv. Lublaňského homiliáře. Slavia 82: 423-435.
- - -. 2017. Některé faktory důležité pro posuzování slovní zásoby v chorvatskohlaholských breviáŕích. Filologija: časopis Razreda za filološke znanosti Hrvatske akademije znanosti i umjetnosti u Zagrebu 68: 193-221.

- - -. 2019. Izbrannye leksemy Knigi Iova v horvatsko-glagoličeskih breviariah, parimejnikah i čet'em perevode. V: Lora Taseva et al., ur. B' 'Igaristikata v Evropa: nastojašte $i$ b' 'dešte, 201216. Sofija: Izdatelstvo Iztok-Zapad.

Temčin, SergejJu. 1995. O razgraničenii leksičeskih arhaizmov i innovacij v cerkovnoslavjanskom tekste: varianty kъnižbnikъ i kъnigočii v spiskah evangelija XI.-XVI. Slavistica Vilnensis 45: 64-81.

Vajs, Josef. 1908. Co značí slova: »по закону римского двора« $\mathrm{V}$ nadpisech hlaholských breviářů chrvatských. V: Jagić-Festschrift. Zbornik u slavu Vatroslava Jagića, 230-234. Berlin: Weidmannsche Buchhandlung.

Valjavec, Matija. 1889-1890. O prevodu psalama u nekijem rukopisima hrvatsko-srpsko i bugarsko-slovenskijem. Rad Jugoslovenske akademije 98: 1-72. 